JIME (Journal of Industrial and Manufacture Engineering), ), 4 (1) Mei 2020

ISSN 2549-6328 (Print) ISSN2549-6336 (Online) DOI : 10.31289/jime.v4i1.2972

JIME (Journal of Industrial and Manufacture Engineering)

Available online http://ojs.uma.ac.id/index.php/jimeＥmail: jime@uma.ac.id

\title{
Analisis Strategi Pemasaran Jasa Percetakan dengan Menggunakan Metode SWOT dan Analyitc Hierarchy Process
}

\section{Marketing Strategy Analysis of Printing Services SWOT Method and Analytical Hierachy Process}

\author{
Andika Pratama $^{\left.*^{1}\right)}$, Willy Tambunan ${ }^{2)}$ dan Farida Djumiati Sitania ${ }^{3)}$ \\ Program Studi Teknik Industri, Fakultas Teknik \\ Universitas Mulawarman, Indonesia
}

Diterima: Oktober 2019; Disetujui: Januari 2020; Dipublikasi: Mei 2020;

*Corresponding author: dikapratama.ap@gmail.com

\begin{abstract}
Abstrak
Badan Pengelola Usaha (BPU) Universitas Mulawarman didirikan untuk mengkoordinasikan seluruh kegiatan usaha di Universitas Mulawarman, baik kegiatan usaha berbasis akademik maupun non akademik, ditingkat Universitas maupun tingkat fakultas atau unit lainnya. M-PRINTING merupakan salah satu usaha percetakan yang diluncurkan oleh BPU Universitas Mulawarman dan posisi yang sangat strategis karena terletak di kawasan Universitas Mulawarman. Permasalahan yang terjadi di M-PRINTING yaitu captive market yang belummaksimal dan pesaing-pesaing yang sudah lama berada diusaha percetakan. Oleh karena itu diperlukan adanya strategi pemasaran yang dapat memecahkan masalah tersebut. Dalam menentukan prioritas strategi pemasaran diperlukan pengambilan keputusan. Dalam penelitian ini menggunakan metode SWOT dan AHP untuk mengetahui strategi yang paling tepat digunakan pada M-Printing. Hasil dari penelitian, diperoleh bobot skor IFE sebesar 2,239 sedangkan pada matrik EFE diperoleh bobot skor sebesar 3,054. Dari bobot bskor yang telah diperoleh, M-Printing bisa melaksanakan strategi tumbuh dan Berkembang. Dari formulasi matrik SWOT didapatkan delapan alternatif yang akan ditentukan bobot prioritas menggunakan AHP. Hasil perhitungan AHP didapatkan alternatif strategi yaitu menambah inovasi produk baru yaitu cetak security print dan watermax tinta silver.
\end{abstract}

Kata kunci: StrategiPemasaran, M-PRINTING, SWOT, Analytical Hierarchy Process (AHP).

\begin{abstract}
Badan Pengelola Usaha (BPU) also coordinated all of business activities in Mulawarman University in academic or non-academic based and even in university level, faculty level or other units. M-PRINTING is a printing services business who launched by BPU Mulawarman University and has a good strategic position because it is located in Mulawarman University region. The problem occured in M-Printing is captive market which not maximal and other competitors who already startedin the same printing services business. Therefore, a marketing strategy is needed to solve the problem. and find the priority of marketing strategy to be able to make decisions. In this study using the SWOT and AHP methods to find out the most appropriate strategy used in M-Printing. The results of the study, obtained weighting IFE score of 2.239 while the EFE matrix obtained score weighting of 3.054. From the weight of the score that has been obtained, M-Printing can implement a growth and development strategy. From the SWOT matrix formulation, there are eight alternatives that will be determined priority weight using AHP. AHP calculation results obtained an alternative strategy is to buy a new product, namely security printing and silver ink watermax.
\end{abstract}

Keywords: marketing strategy, M-PRINTING, SWOT, Analytical Hierarchy Process (AHP)

How to Cite: Pratama, A, Tambunan, W, dan Sitania, F.D. (2020), Analisis Strategi Pemasaran Jasa Percetakan dengan Menggunakan Metode SWOT dan Analytic Hierarchy Process, JIME Uournal of Industrial and Manufacture Engineering), 4(1): 12 - 21 



\section{PENDAHULUAN}

Kemunculan

teknologi digital membuka peluang di berbagai bidang industri. Teknologi komputer dan printer yang ada sekarang telah memungkinkan kita untuk mencetak tidak hanya teks dan gambar sederhana, namun sudah dapat mencetak dengan hasil kualitas foto. Digital printing kini sedang menjadi trend khususnya untuk ke pentingan promosi perusahaan. Disamping itu, permintaan akan produk digital printing semakin meningkat seiring dengan banyaknya perusahaan digital printing baru. Cetak digital (digital printing) merupakan proses pencetakan suatu gambar atau desain ke media cetak seperti kertas, kain atau bahan lainnya secara langsung dari computer melalui alat cetak dimana pencetakan dilakukan dan dikontrol secara digital tanpa melalui proses pembuatan acuan cetak (Yuniarti, Y, \&Mauliana, S., 2012).

Universitas Mulawarman memiliki sebuah badan yang mengelola seluruh bisnisnya yaitu Badan Pengelola Usaha (BPU). BPU bertugas untuk mengelola bisnis-bisnis yang ada sebagai pemasukan universitas diluar dari Uang Kuliah Tungga (UKT). Salah satu jenis usaha yang dikelola oleh BPU yaitu M-Printing. Pentingnya jasa percetakan sudah menjadi kebutuhan setiap orang, khususnya civitas akademika Universitas Mulawarman, baik untuk kebutuhan akademik maupun kegiatan non-akademik. Maka dari itu BPU membuka jasa percetakan dengan nama M-Printing. M-Printing merupakan salah satu bidang usaha milik Universitas Mulawarman yang dikelola BPU. MPrinting ini bergerak di bidang jasa percetakan dengan pelayanan berupa fotokopi, penjilidan, X\&Y Banner, spanduk, alat tulis kantor (ATK), dan lain-lain.

Meskipun usaha percetakan ini terbilang baru akan tetapi, M-Printing ini memiliki kekuatanya itu captive market yang dimiliki dan diharapkan percetakan ini akan menjadi pemasok utama kebutuhan percetakan Universitas Mulawarman sehingga tidak perlu lagi adanya outsource.

Persaingan akan semakin sengit karena teknologi pendukung pasar digital printing terbuka untuk dikuasai dan diimplementasikan. Strategi pemasaran merupakan senjata bagi perusahaan dalam menghadapi persaingan bisnis digital printing. Beberapa masalah yang harus dihadapi oleh M-Printing terkait dengan pemasaranya itu captive market yang belum maksimal dan pesaing-pesaing yang sudah lama berada di usaha percetakan. Oleh karena itu diperlukan adanya strategi pemasaran yang dapat memecahkan masalah tersebut.

Salah satu metode yang digunakan dalam strategi pemasaran M-Printing ini adalah SWOT yang meliputi strength, weakness, opportunity, dan threat. Menurut David (2012), matriks kekuatan, kelemahan, peluang, dan ancaman adalah alat pencocokan yang penting yang membantu para manajer mengembangkan empat jenis strategi yaitu Strategi SO (Strengths-Threats), Strategi WO (WeaknessOpportunities), Strategi ST (StrengthsThreats), dan Strategi WT (WeaknessThreats). Tujuan pengunaan metode SWOT pada M-Printing ini adalah untuk mengidentifikasi kekuatan, kelemahan, peluang dan ancaman, menentukan strategi M-Printing berdasarkan faktor eksterna l(luar) dan internal (dalam) serta mendapatkan prioritas strategi. Namun, faktor-faktor SWOT tersebut perlu diidentifikasi besaran dampaknya terhadap tujuan dari M-Printing. 
Pratama, A, Tambunan, W, dan Sitania, F.D. , Analisis Strategi Pemasaran Jasa Percetakan Dengan Menggunakan Metode SWOT Dan Analytic Hierarchy Process

Selanjutnya setelah didapatkan alternatif strategi dari SWOT dilakukan pembobotan prioritas dengan menggunakan metode Analytic Hierarchy Process (AHP). Menurut Rahma Sari dan Indra Sensuse, (2008) AHP (Analytic Hierarchy Process) merupakan pendekatan dasar untuk pengambilan keputusan AHP juga metode yang dapat menerjemahkan karakter kualitatif faktor-faktor SWOT yang telah didapatkan menjadi karakter yang kuantitatif menggunakan teknik pembobotan yang dilakukan untuk memilih prioritas dari alternatif strategi yang ada agar mengetahui alternatif strategi pemasaran yang paling efektif untuk dijalankan oleh M-Printing. Maka diharapkan analisis tersebut dapat membantu M-Printing dalam menentukan strategi prioritas untuk menghadapi pesaing-pesaing yang sudah lama bergelut di usaha percetakan dan memaksimalkan potensi captive market tersebut

Pendekatan dengan metode AHP SWOT sudah banyak diterapkan oleh beberapa peneliti seperti Rahman (2011), Rohmatulloh dan Winarni (2012), Saediman dkk (2015), Affandy (2017). Kombinasi SWOT-AHP dapat digunakan untuk pengambilan keputusan dalam menentukan strategi prioritas dari masing-masing strategi yang diusulkan (Rohmatulloh dan Winarni, 2012)

\section{METODE PENELITIAN}

Penelitian ini didesain dengan pendekatan secara kualitatif dan kuantitatif karena pada penelitian ini dilakukan dengan dua tahap, yaitu dengan analisis SWOT dan AHP. Analisis SWOT ini yang akan digunakan peneliti untuk menentukan alternatif-alternatif strategi pemasaran. AHP akan digunakan setelah diperoleh hasil dari analisis SWOT, AHP akan berfungsi sebagai alat untuk menentukan strategi mana yang harus diprioritaskan oleh M-Printing. Dalam penelitian inijenis data yang digunakan data primer dan sekunder. Dalam memperoleh data primer dilakukan dengan tahapan interview dan kuisioner kepada sales dan marketing M-Printing yaitu bapak Ilham Ramadan dan pimpinan usaha yaitu bapak Iqbal. Adapun data sekunder bisa diperoleh dari literatur atau internet.

\section{HASIL DAN PEMBAHASAN}

Faktor-faktor yang diperoleh dari pengumpulan data yang sudah dilakukan selanjutnya akan dilakukan pembobotan dan rating terhadap setiap faktor. Menurut Sedarmayanti (2014), Eksternal Factor Evaluation (EFE) matriks digunakan untuk mengevaluasi faktor eksternal perusahaan. Data eksternal dikumpulkan untuk menganalisis hal-hal menyangkut persoalan dipasar industri. Matriks internal faktor digunakan untuk mengetahui faktor internal perusahaan berkaitan dengan kekuatan dan kelemahan yang dianggap penting Hasil pembobotan dan rating pada setiap faktor dapat dilihat pada tabel 1 dan tabel 2 sebagai berikut:

Tabel 1. MatriksIFE

\begin{tabular}{|l|c|c|c|}
\hline \multicolumn{1}{|c|}{ Faktor Internal } & Bobot & Rating & Skor \\
\hline \multicolumn{1}{|c|}{ Kekuatan } & & & \\
\hline $\begin{array}{l}\text { Universitas Mulawarman } \\
\text { memiliki mitra resmi } \\
\text { dalam pengadaan } \\
\text { percetakan dan } \\
\text { Advertising }\end{array}$ & 0.097 & 4 & $\begin{array}{c}0.3 \\
89\end{array}$ \\
\hline $\begin{array}{l}\text { Harga yang ditawarkan } \\
\text { relative bersaing }\end{array}$ & 0.097 & 3 & 0.2 \\
\hline $\begin{array}{l}\text { Kualitas produk } \\
\text { percetakan baik karena } \\
\text { ditangaini SDM } \\
\text { berkualitas }\end{array}$ & 0.100 & 3.5 & 0.3 \\
\hline Lokasi usaha yang & 0.083 & 3 & 0.2 \\
\hline
\end{tabular}


JIME (Journal of Industrial and Manufacture Engineering), 4(1): 12 - 21

\begin{tabular}{|l|c|c|c|}
\hline \multicolumn{1}{|c|}{ Faktor Internal } & Bobot & Rating & Skor \\
\hline $\begin{array}{l}\text { strategis dan mudah } \\
\text { untuk dituju }\end{array}$ & & & 50 \\
\hline $\begin{array}{l}\text { Teknologi mesin yang } \\
\text { digunakan sangat baik } \\
\text { untuk produksi } \\
\text { beberapa produk yang } \\
\text { memiliki kecepatan } \\
\text { produksi yang tinggi }\end{array}$ & 0.089 & 4 & 0.3 \\
\hline \multicolumn{1}{|c|}{ Kelemahan } & & & \\
\hline $\begin{array}{l}\text { Variasi produk yang } \\
\text { tinggi sehingga sukar } \\
\text { menentukan harga } \\
\text { diawal }\end{array}$ & 0.092 & 1.5 & 0.1 \\
\hline $\begin{array}{l}\text { Standart pelayanan yang } \\
\text { belum dirancang }\end{array}$ & 0.117 & 1 & 0.1 \\
\hline $\begin{array}{l}\text { Manajemen internal } \\
\text { masih bersifat } \\
\text { tradisional }\end{array}$ & 0.086 & 1 & 0.0 \\
\hline Kurangnya tenaga kerja & 0.114 & 2 & 0.2 \\
\hline $\begin{array}{l}\text { Belum memiliki } \\
\text { performance on-time } \\
\text { yang baik }\end{array}$ & 0.125 & 1 & 0.1 \\
\hline \multicolumn{1}{|c|}{ Total } & 1 & 25 \\
\hline
\end{tabular}

\begin{tabular}{|l|c|c|c|}
\hline Faktor Eksternal & Bobot & Rating & Skor \\
\hline $\begin{array}{l}\text { Persaingan semakin } \\
\text { ketat kemudahan } \\
\text { pesaing baru untuk } \\
\text { memasuki industry }\end{array}$ & 0.108 & 2.5 & 0.271 \\
\hline $\begin{array}{l}\text { Persaingan pasar yang } \\
\text { terus mengalami } \\
\text { perkembangan }\end{array}$ & 0.119 & 3 & 0.358 \\
\hline $\begin{array}{l}\text { Tidak Stabilnya Harga } \\
\text { Bahan Baku }\end{array}$ & 0.122 & 3 & 0.367 \\
\hline Total & 1.000 & & 3.054 \\
\hline
\end{tabular}

Berdasarkan hasil pada tabel 1 dan 2 Nilai total skor faktor-faktor strategis internal M-Printing adalah sebesar 2.329, sedangkan nilai total skor atas faktorfaktor strategis eksternal adalah sebesar 3,054. Hal ini dapat diartikan bahwa faktor strategis eksternal memiliki pengaruh yang lebih besar dibandingkan dengan faktor strategis internal.

Berdasarkan hasil yang diperoleh

Tabel 2.Matriks EFE

\begin{tabular}{|c|c|c|c|}
\hline Faktor Eksternal & Bobot & Rating & Skor \\
\hline \multicolumn{4}{|l|}{ Peluang } \\
\hline \begin{tabular}{lr}
\multicolumn{3}{l}{ Banyaknya aktivitas } \\
yang memerlukan \\
percetakan r di \\
Universitas \\
Mulawarman
\end{tabular} & 0.092 & 3.5 & 0.321 \\
\hline $\begin{array}{l}\text { Diberlakukannya } \\
\text { proses pengadaan } \\
\text { barang dan jasa } 1 \\
\text { pintu melalui pejabat } \\
\text { pembuat komitmen } \\
\text { (ppk) Universitas } \\
\text { Mulawarman } \\
\end{array}$ & 0.089 & 3 & 0.267 \\
\hline $\begin{array}{l}\text { Dukungan pimpinan } \\
\text { Universitas } \\
\text { Mulawarman } \\
\text { terhadap kemajuan } \\
\text { m-printing melalui } \\
\text { regulasi }\end{array}$ & 0.117 & 4 & 0.467 \\
\hline $\begin{array}{l}\text { Kontinuitas } \\
\text { pengadaan produk- } \\
\text { produk percetakan } \\
\text { dan advertising } \\
\end{array}$ & 0.089 & 3 & 0.267 \\
\hline $\begin{array}{l}\text { Captive market yang } \\
\text { luas }\end{array}$ & 0.114 & 3.5 & 0.399 \\
\hline \multicolumn{4}{|l|}{ Ancaman } \\
\hline $\begin{array}{l}\text { Usaha sejenis yang } \\
\text { berada berdekatan } \\
\text { dengan lokasi saat ini }\end{array}$ & 0.078 & 2 & 0.194 \\
\hline $\begin{array}{l}\text { Kebebasan memilih } \\
\text { bagi konsumen umum }\end{array}$ & 0.072 & 2 & 0.144 \\
\hline
\end{tabular}
dari matriks IFE dan EFE dapat disusun dalam matriks Internal-Eksternal. Menurut Rangkuti, (2001) pada matriks ini bertujuan untuk memperoleh strategi bisnis pada posisi yang akan dicapai. Hasil matriks IE (internal eksternal) data dapat dilihat pada Gambar 1 sebagai berikut:

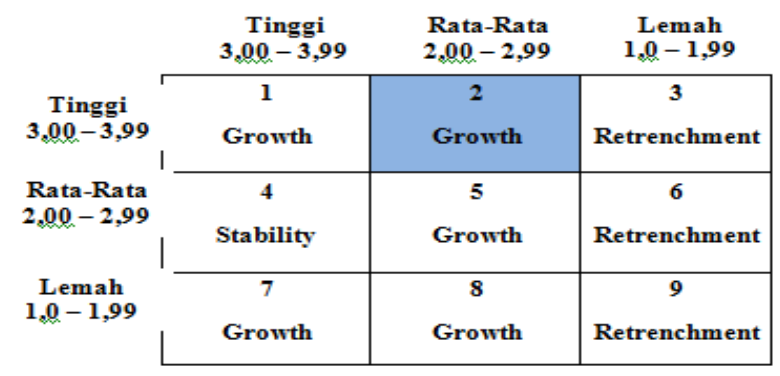

Gambar 1.Matriks IE Percetakan M-Printing

Berdasarkan hasil pada gambar 1 dapat dilihat M-Printing berada pada posisi sel 2. Hal ini menunjukkan bahwa strategi yang paling baik yang digunakan oleh M-Printing adalah strategi Grow and Build (Tumbuh dan Berkembang). Strategi yang dapat digunakan pada posisi grow and build ini adalah strategi penetrasi 
Pratama, A, Tambunan, W, dan Sitania, F.D. , Analisis Strategi Pemasaran Jasa Percetakan Dengan Menggunakan Metode SWOT Dan Analytic Hierarchy Process

pasar, pengembangan pasar, dan Matching Strategy

pengembangan produk.

Hasil dari analisis faktor internal dan faktor eksternal pemasaran M-Printing selanjutnya akan disusun dalam beberapa alternatif strategi dengan menggunakan matriks SWOT. Hasil dari analisis matriks SWOT M-Printing adalah sebagai berikut:

\section{Strategi SO (Strengths-Opportunities)}

a. Memberikan promo untuk eveneven tertentu dan pesanan dalam jumlah banyak

b. Menjalin kerjasama dengan organisasi mahasiswa yang membutuhkan jasa percetakan di Universitas Mulawarman.

\section{Strategi ST (Strengths-Threats)}

a. Meningkatkan kegiatan promosi dengan memanfaatkan teknologi yang ada

b. Menambah jumlah relasi dengan supplier dan rekanan sehingga memudahkan untuk pencarian bahan alternatif yang lebih terjangkau

\section{Strategi WO (Weaknesses- Opportunities)}

a. Menambah inovasi produk baru yang sebelumnya tidak ada di MPrinting seperti cetak security print dan watermax tinta silver

\section{Strategi WT (Weakness-Threats)}

a. Menjalin kerjasama dengan instansi yang membutuhkan jasa percetakan seperti bank, sekolah, kantor pemerintah samarinda, dan perusahaan.

b. Menyediakan layanan antar yang dapat mengantar pesanan tepat waktu c. Meningkatkan pelayanan seperti pelayanan cetak yang bisa ditunggu.
Berdasarkan skor yang didapatkan dari matriks IE menunjukkan bahwa posisi M-Printing Universitas Mulawarman berada pada sel II. Pada posisi ini strategi yang tepat untuk digunakan adalah tumbuh dan membangun (grow and build). Strategi yang dapat digunakan pada posisi grow and build ini adalah strategi penetrasi pasar, pengembangan pasar, dan pengembangan produk yang dapat dilihat pada Tabel 3 sebagai berikut:

\begin{tabular}{|c|c|}
\hline $\begin{array}{l}\text { Penetrasi } \\
\text { Pasar }\end{array}$ & $\begin{array}{l}\text { 1. } \begin{array}{lr}\text { Meningkatkan } \\
\text { promosi }\end{array} \\
\text { memanfaatkan teknologi yang } \\
\text { ada }\end{array}$ \\
\hline $\begin{array}{l}\text { Pengemba } \\
\text { ngan Pasar }\end{array}$ & 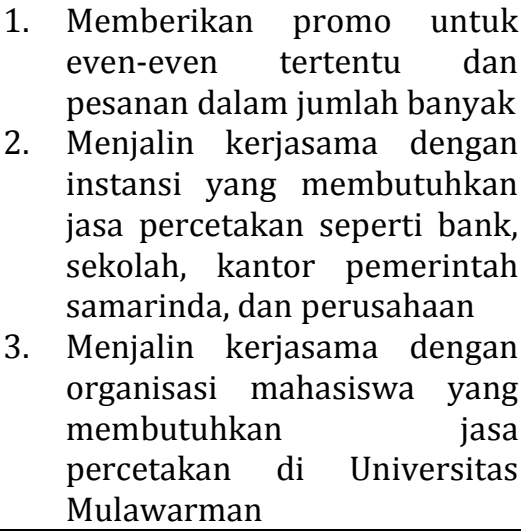 \\
\hline $\begin{array}{l}\text { Pengemba } \\
\text { ngan } \\
\text { Produk }\end{array}$ & 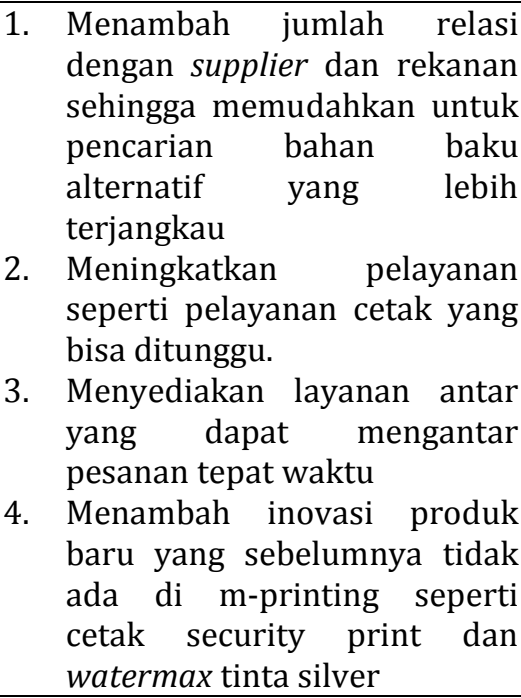 \\
\hline
\end{tabular}

\section{Analytic HierarkiProcess(AHP)}

Menurut (Hardiasnyah, dkk, 2015), Analytic Herarchy Process merupakan alat pengambil keputusan yang menguraikan suatu permasalahan kompleks dalam 
struktur hirarki dengan banyak tingkatan yang terdiri dari tujuan, kriteria, dan alternatif struktur hirarki strategi pemasaran percetakan M-Printing Universitas Mulawarman dapat dilihat pada Gambar 2 adalah sebagai berikut:

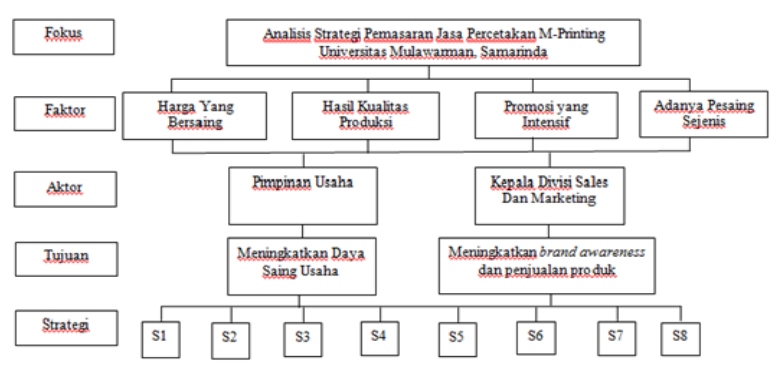

Gambar 3 Struktur Hierarki Strategi Pemasaran M-Printing Universitas Mulawarman

Keterangan:

S1 Meningkatkan kegiatan promosi dengan memanfaatkan teknologi yang ada

S2 Memberikan Promo untuk even-even tertentu dan pesanan dalam jumlah banyak

S3 Menjalin kerjasama dengan instansi yang membutuhkan jasa percetakan seperti bank, sekolah, kantor pemerintah samarinda, dan perusahaan

S4 Menjalin kerjasama dengan organisasi mahasiswa yang membutuhkan jasa percetakan di Universitas Mulawarman

S5 Menambah jumlah relasi dengan supplier dan rekanan sehingga memudahkan untuk pencarian bahan baku alternatif yang lebih terjangkau

S6 Meningkatkan pelayanan seperti pelayanan cetak yang bisa ditunggu

S7 Menyediakan layanan antar yang dapat mengantar pesanan tepat waktu

S8 Menambah inovasi produk baru yang sebelumnya tidak ada di M-Printing seperti cetak security print dan watermaxtinta silver.

Berikut merupakan penjelasan struktur hierarki pada masing-masing level dalam analisis AHP:

\section{Ultimate Goal AHP}

Ultimate goal yang menjadi inti dari permasalahan ini adalah pemilihan strategi yang efektif untuk dilakukan perusahaan dalam pemasaran jasa percetakan M-Printing

\section{Faktor-faktor AHP}

Faktor-faktor yang diidentifikasi dan berpengaruh dalam pemenuhan ultimate goal strategi pemasaran perusahaan adalah:

\section{a. Harga Yang Bersaing}

Harga yang bersaingmenjadi salah satu faktor penentu dalam strategi pemasaran. Dalam hal pemberian harga terhadap penawaran jasa, perusahaan berusaha untuk menjaga loyalitas pelanggan dan dapat bersaing dengan kompetitor.

\section{b. Hasil KualitasProduksi}

Pada faktor ini marketing dan sales harus memberikan jaminan kepada pelanggan maupun calon pelanggan

bahwa jika mereka mempercayakan mencetak di M-Printing, maka hasil kualitas produksi yang didapatakan sesuai harapan.

\section{c. Promosi Yang Intensif}

Semakin ketatnya persaingan menyebabkan terjadinya kompetisi dalam memperebutkan jasa cetak dan kepercayaan konsumen. Salah satu faktor yang harus diperhatikan adalah perusahaan harus melakukan promosi 
Pratama, A, Tambunan, W, dan Sitania, F.D. , Analisis Strategi Pemasaran Jasa Percetakan Dengan Menggunakan Metode SWOT Dan Analytic Hierarchy Process

yang intensif. Dengan dilakukannya dan bersaing dengan competitor

promosi yang intensif diharapkan

perusahaan dapat menjadi pemenang dalam persaingan terhadap kompetitor.

\section{d. Adanya Pesaing Sejenis}

Terbentuknya strategi ini karena adanya pesaing sejenis, baik pesaing yang sudah lama berdiri maupun pesaing baru. Maka dengan adanya strategi ini perusahaan mampu bersaing ataupun menjadi pemenang dalam persaingan terhadap kompetitor.

\section{Aktor Yang BerperanDalam AHP}

Aktor - aktor yang bereperan dalam pemenuhan faktor-faktor pada penentuan strategi pemasaran di perusahaan adalah:

\section{a. Pimpinan Usaha}

Pimpinan usaha menjadi aktor yang bertanggungjawab paling besar dalam menetapkan dan mengambil keputusan mengenai strategi atau kebijakan perusahaan.

\section{b. Kepala divisi sales dan marketing}

Kepala divisi sales dan marketing bertanggungjawab terhadap keseluruhan proses pemasaran. Aktor ini juga bertanggungjawab terhadap harga, kualitas produksi, promosi dan brand awareness.

\section{Tujuan dalam AHP}

Tujuan yang dapat dipenuhi oleh para aktor adalah sebagai berikut.

\section{a. Meningkatkan Daya Saing}

Tujuan ini untuk meningkatkan kualitas produk maupun pelayanan dikarenakan ketatnya persaingan dibidang percetakan, maka dari itu M-Printing perlu meningkatkan segala aspek agar bertahan

\section{b. Meningkatkan Brand Awareness dan Penjualan Produk \\ Tujuan ini untuk memperkenalkan} kepada calon pembeli atau konsumen untuk mengenali maupun mengingat sebuah merek. Dalam hal ini tentunya bisa meliputi nama, gambar atau logo, serta slogan tertentu yang digunakan $M$ Printing untuk mempromosikan produk-produknya.

5. Alternatif strategi yang dimasukkan kedalam struktur AHP didapat dari analisis SWOT. Terdapat 8 alternatif strategi yang dapat dilakukan perusahaan, yaitu :

a. Meningkatkan kegiatan promosi dengan memanfaatkan teknologi yang ada

b. Memberikan promo untuk eveneven tertentu dan pesanan dalam jumlah banyak

c. Menjalin kerjasama dengan instansi yang membutuhkan jasa percetakan seperti bank, sekolah, kantor pemerintah samarinda, dan perusahaan

d. Menjalin kerjasama dengan organisasi mahasiswa yang membutuhkan jasa percetakan di Universitas Mulawarman

e. Menambah jumlah relasi dengan supplier dan rekanan sehingga memudahkan untuk pencarian bahan baku alternatif yang lebih terjangkau

f. Meningkatkan pelayanan seperti pelayanan cetak yang bisa ditunggu 
g. Menyediakan layanan antar yang dapat mengantar pesanan tepat waktu

h. Menambah inovasi produk baru yang sebelumnya tidak ada di M-Printing seperti cetak security print dan watermax tinta silver.

Berdasarkan struktur hierarki yang diperoleh selanjutnya dilakukan pengolahan secara horizontal yang didapat dari perbandingan berpasangan dan uji konsistensi. Hasil dari pengolahan secara horizontal sebagai berikut:

1. Hasil Elemen Faktor terhadap Fokus. Berikut ini adalah table perbandingan elemen faktor terhadap fokus yang dapat dilihat pada Tabel 4 sebagai berikut:

Tabel 4. Hasil Elemen Faktor terhadap Fokus

\begin{tabular}{|c|l|c|c|}
\hline \multirow{2}{*}{ Elemen-ElemenFaktor } & \multicolumn{2}{c|}{ Fokus } \\
\cline { 3 - 4 } & Bobot & $\begin{array}{c}\text { Priorit } \\
\text { as }\end{array}$ \\
\hline F1 & Harga Yang Bersaing & 0.340 & $\mathbf{2}$ \\
\hline F2 & $\begin{array}{l}\text { Hasil Kualitas } \\
\text { Produksi }\end{array}$ & 0.368 & $\mathbf{1}$ \\
\hline F3 & $\begin{array}{l}\text { Promosi Yang } \\
\text { Intenisif }\end{array}$ & 0.178 & 3 \\
\hline F4 & $\begin{array}{l}\text { Adanya Pesaing } \\
\text { Sejenis }\end{array}$ & 0.115 & $\mathbf{4}$ \\
\hline \multicolumn{2}{|c|}{ RasioInkonsistensi (CR) } & \multicolumn{2}{|c|}{$\mathbf{0 . 8 9}$} \\
\hline
\end{tabular}

\section{Hasil Elemen Aktor terhadap Faktor.}

Berikut ini hasil pengolahan data dapat dilihat pada Tabel 5sebagai berikut:

Tabel 5.Hasil Elemen aktor terhadap Faktor

\begin{tabular}{|l|c|c|c|c|}
\hline $\begin{array}{c}\text { Elemen-elemen } \\
\text { Aktor }\end{array}$ & F1 & F2 & F3 & F4 \\
\hline $\begin{array}{l}\text { Pimpinan Usaha } \\
\text { (A1) }\end{array}$ & 0.333 & 0.83 & 0.25 & 0.50 \\
\hline $\begin{array}{l}\text { Kepala Divisi Sales } \\
\text { dan Marketing (A2) }\end{array}$ & 0.667 & 0.17 & 0.75 & 0.50 \\
\hline $\begin{array}{c}\text { RasioInkonsistensi } \\
\text { (CR) }\end{array}$ & $\mathbf{0}$ & $\mathbf{0}$ & $\mathbf{0}$ & $\mathbf{0}$ \\
\hline
\end{tabular}

3. Hasil ElemenTujuanterhadapAktor

Berikut hasil pengolahan data dapat dilihat pada Tabel 6 sebagai berikut:

Tabel 6. Hasil Elemen Tujuan Terhadap Aktor

\begin{tabular}{|l|c|c|}
\hline \multicolumn{1}{|c|}{ Elemen-elemenTujuan } & A1 & A2 \\
\hline $\begin{array}{l}\text { Meningkatkan daya saing usaha } \\
\text { (T1) }\end{array}$ & 0.83 & 0.75 \\
\hline $\begin{array}{l}\text { Meningkatkan brand awareness } \\
\text { dan penjuala nproduk (T2) }\end{array}$ & 0.17 & 0.25 \\
\hline \multicolumn{1}{|c|}{ RasioInkonsistensi (CR) } & $\mathbf{0}$ & $\mathbf{0}$ \\
\hline
\end{tabular}

\section{Hasil Elemen Strategi terhadap Tujuan}

Berikut ini hasil pengolahan data dapat dilihat pada Tabel 7 sebagai berikut:

Tabel 7. Hasil Elemen Strategi Terhadap Tujuan

\begin{tabular}{|l|l|l|}
\hline Elemen - elemen Alternatif & T1 & T2 \\
\hline $\begin{array}{l}\text { Meningkatkan kegiatan promosi } \\
\text { dengan } \\
\text { teknologi yang ada (S1) }\end{array}$ & 0.033 & 0.189 \\
\hline $\begin{array}{l}\text { Memberikan promo untuk } \\
\text { even-even tertentu dan pesanan } \\
\text { dalam jumlah banyak (S2) }\end{array}$ & 0.081 & 0.194 \\
\hline $\begin{array}{l}\text { Menjalin kerjasama dengan } \\
\text { instansi yang membutuhkan } \\
\text { jasa percetakan seperti bank, }\end{array}$ & 0.055 & 0.206 \\
$\begin{array}{l}\text { sekolah, kantor pemerintahan } \\
\text { samarinda, dan perusahaan } \\
\text { (S3) }\end{array}$ & 0.065 & 0.182 \\
\hline $\begin{array}{l}\text { Menjalin kerjasama dengan } \\
\text { organisasi-organisasi di Pelayanan } \\
\text { mahasiswa yang membutuhkan } \\
\text { jasa percetakan di Universitas } \\
\text { Mulawarman (S4) }\end{array}$ & 0.151 & 0.061 \\
\hline $\begin{array}{l}\text { Menambah jumlah relasi } \\
\text { dengan supplier dan rekanan } \\
\text { sehingga memudahkan untuk } \\
\text { pencarian bahan alternatif yang } \\
\text { lebih terjangkau (S5) }\end{array}$ & 0.129 & 0.026 \\
\hline $\begin{array}{l}\text { Meningkatkan pelayanan cetak yang } \\
\text { seperti pelayanan } \\
\text { bisa ditunggu (S6) }\end{array}$ & 0.178 & 0.060 \\
\hline $\begin{array}{l}\text { Menyediakan layanan antar } \\
\text { yang dapat mengantar pesanan } \\
\text { tepat waktu (S7) }\end{array}$ & $\mathbf{0 . 0 5}$ & $\mathbf{0 . 0 6}$ \\
\hline $\begin{array}{l}\text { Menambah inovasi produk baru } \\
\text { yang sebelumnya tidak ada di } \\
\text { M-Printing seperti cetak } \\
\text { security print dan watermax } \\
\text { tinta silver (S8) }\end{array}$ & $\mathbf{5}$ \\
\hline RasioInkonsistensi (CR) & 0.307 & 0.081 \\
\hline
\end{tabular}


Pratama, A, Tambunan, W, dan Sitania, F.D. , Analisis Strategi Pemasaran Jasa Percetakan Dengan Menggunakan Metode SWOT Dan Analytic Hierarchy Process

Berdasarkan perhitungan perbandingan berpasangan dan penentuan prioritas yang telah dilakukan di atas maka hasil pengolahan secara horizontal untuk elemen strategi terhadap tujuan. Adapun tujuan yang ingin dicapai yaitu tujuan meningkatkan daya saing usaha dan meningkatkan brand awareness dan penjualan produk strategi yang terpilih adalah menambah inovasi produk baru yang sebelumnya tidak ada di MPrinting seperti cetak security print dan watermax tinta silver dengan bobot 0.307 dan menjalin kerjasama dengan instansi yang membutuhkan jasa percetakan seperti bank, sekolah, kantor pemerintahan samarinda, dan perusahaan 0.206 .

Setelah melakukan pengolahan secara horizontal, selanjutnya perlu melakukan pengolahan secara vertikal yang bertujuan menyusun dan melihat prioritas menyeluruh setiap elemen pada tingkat tertentu terhadap sasaran utama hirarki. Penjelasan dari setiap elemen dengan penilaian secara vertikal pada tingkatan hierarki yang berbeda dalam penyusunan strategi pemasaran percetakan M-Printing Universitas Samarinda dijelaskan sebagai berikut :

\section{Fokus}

Fokus pada hirarki ini adalah strategi pemasaran percetakan M-Printing Universitas Mulawarman, Samarinda

\section{Faktor}

Berikut hasil pengolahan data secara vertikal faktor dapat dilihat pada Tabel 8 sebagai berikut:
Tabel 8. Hasil Pengolahan Vertikal Faktor

\begin{tabular}{|c|l|c|c|}
\hline \multicolumn{2}{|c|}{ Elemen-ElemenFaktor } & \multicolumn{2}{c|}{ Fokus } \\
\cline { 3 - 4 } & Bobot & Prioritas \\
\hline F1 & Harga Yang Bersaing & 0.340 & $\mathbf{2}$ \\
\hline F2 & Hasil KualitasProduksi & 0.368 & $\mathbf{1}$ \\
\hline F3 & Promosi Yang Intenisif & 0.178 & $\mathbf{3}$ \\
\hline F4 & Adanya Pesaing Sejenis & 0.115 & $\mathbf{4}$ \\
\hline
\end{tabular}

\section{Aktor}

Berikut hasil pengolahan data secara vertikal aktor dapat dilihat pada Tabel 9 sebagai berikut:

Tabel 9. Hasil Pengolahan Vertikal Aktor

\begin{tabular}{|l|c|c|}
\hline \multicolumn{1}{|c|}{ ElemenAktor } & Bobot & Prioritas \\
\hline Pimpinan Usaha (A1) & 0.478 & 2 \\
\hline $\begin{array}{l}\text { Kepala Divisi Sales dan } \\
\text { Marketing (A2) }\end{array}$ & 0.522 & 1 \\
\hline
\end{tabular}

4. Tujuan

Berikut hasil pengolahan data secara vertikal tujuan dapat dilihat pada Tabel 10 sebagai berikut:

Tabel 10. Hasil PengolahanVertikal Tujuan

\begin{tabular}{|l|c|c|}
\hline Elemen Tujuan & Bobot & Prioritas \\
\hline $\begin{array}{l}\text { Meningkatkan daya } \\
\text { saing usaha (T1) }\end{array}$ & 0.790 & 1 \\
\hline $\begin{array}{l}\text { Meningkatkan brand } \\
\text { awareness dan } \\
\text { penjualan produk (T2) }\end{array}$ & 0.210 & 2 \\
\hline
\end{tabular}

\section{Alternatif Strategi}

Berikut hasil pengolahan data secara vertikal alternatif strategi dapat dilihat pada Tabel 11 sebagai berikut:

Tabel 11. hasil pengolahan vertikal alternatif strategi:

\begin{tabular}{|c|c|c|}
\hline & Bobot & Prioritas \\
\hline S1 & 0.111 & 6 \\
\hline S2 & 0.138 & 2 \\
\hline S3 & 0.131 & 3 \\
\hline S4 & 0.124 & 4 \\
\hline S5 & 0.078 & 8 \\
\hline S6 & 0.106 & 7 \\
\hline S7 & 0.119 & 5 \\
\hline S8 & 0.194 & 1 \\
\hline
\end{tabular}


Berdasarkan pengolahan secara vertikal element alternatif strategi menempatkan pilihan strategi berdasarkan prioritasnya. Prioritas pertama yakni menambah inovasi produk baru yang sebelumnya tidak ada di MPrinting seperti cetak security print dan watermax tinta silver $(0,194)$.

\section{SIMPULAN}

Berdasarkan hasil penelitian dapat diambil kesimpulan bahwa kekuatan utama dari M-Printing yaitu Universitas Mulawarman memiliki mitra resmi dalam pengadaan percetakan dan Advertising (0.389). Faktor yang menjadi kelemahan utama percetakan M-Printing Universitas Mulawarman adalah kurangnya tenaga kerja dengan skor (0.228). Alternatif strategi pemasaran yang tepat setalah dilakukan berdasarkan kondisi percetakan M-Printing Universitas Mulawarman Samarinda saat ini adalah meningkatkan kegiatan promosi dengan memanfaatkan teknologi yang ada, memberikan promo untuk even-even tertentu dan pesanan dalam jumlah banyak, menjalin kerjasama dengan instansi yang membutuhkan jasa percetakan seperti bank, sekolah, kantor pemerintah samarinda, dan perusahaan, menjalin kerjasama dengan organisasi mahasiswa yang membutuhkan jasa percetakan di Universitas Mulawarman, menambah jumlah relasi dengan supplier dan rekanan sehingga memudahkan untuk pencarian bahan baku alternatif yang lebih terjangkau, meningkatkan pelayanan seperti pelayanan cetak yang bisa ditunggu, menyediakan layanan antar yang dapat mengantar pesanan tepat waktu, dan menambah inovasi produk baru yang sebelumnya tidak ada di MPrinting seperti cetak security print dan watermaxtinta silver. Alternatif strategi yang paling diprioritaskan yaitu menambah inovasi produk baru yang sebelumnya tidakada di M-Printing seperti cetak security print dan watermax tinta silver $(0,194)$.

\section{DAFTAR PUSTAKA}

Affandy, Moh Rizki., (2017). Perencanaan Strategi Pemasaran Perhiasan Imitasi Dengan Metode Analisis Swot Dan Analytical Hierarchy Process (Studi Kasus : Ud. Aqila), Jurnal MATRIK p-ISSN : 1693-5128 Volume XVIII No.1.

David, F .R. (2012). Strategic Management: Manajemen Strategis Konsep. Salemba Empat, Bandung

Hardiyansyah, A., dkk., (2015), Analisis Strategi Pemasaran Usaha Mie Basah (Studi Kasus Di Pd. Lugina - Garut). Jurnal Kalibrasi Sekolah Tinggi Teknologi Garut, vol. 13, no. 1.

Rahma Sari, F, dan Indra Sensue., (2008). Penerapan Metode Analytic Hierarchy Process Dalam Sistem Penunjang Keputusan Untuk Pemilihan Asuransi, Jurnal Sistem Informasi MTI-UI, vol. 4, no. 2. Jakarta: PT Gramedia Pustaka Utama.

Rahman, N.T., (2011). Analysis of Indonesia Agro industry Competitiveenessin

Nanoteknology Development Perspective Using SWOT AHP method. International Journal of business and manajement. 6(8).

Rangkuti, Freddy., 2001. Analisis SWOT Teknik Membedah Kasus Bisnis. Jakarta: PT Gramedia Pustaka Utama.

Rohmatulloh, R., \& Winarni, S. (2012). Evaluasi Prioritas Strategi SWOT dengan

Analytical Hierarchy Process. Seminar Nasional Statistika III Universitas Pandjajaran, 3, 1-8.

Saediman, H., Limi, M. A., \& Indarsyih, Y. (2015). Aplikasi SWOT-AHP Untuk Menganalisis Faktor-Faktor Yang Mempengaruhi Pengembangan Komoditas Padi Sawah Di Provinsi Sulawesi Tenggara, 415-426.

Sedarmayanti. (2014). Manajemen Strategi, Cetakan Kesatu. Refika Aditama, Bandung.

Yuniarti, Y, dan Mauliana, S., (2012), Strategi Pemasaran Produk Digital Printing Pada CV. Fnb Digital Jambi, Jurnal Ilmiah Jurusan Manajemen Fakultas Ekonomi Universitas Jambi, vol. 1, no. 1. 